\title{
Inheritance of male sterility in apricot
}

\author{
Burgos L.* and Egea J. \\ Departamento de Mejora y Patología Vegetal, CEBAS-CSIC, \\ Apartado de Correos 4195, 30080-Murcia, Spain. \\ *Author for correspondence. E-mail: burgos@cebas.csic.es
}

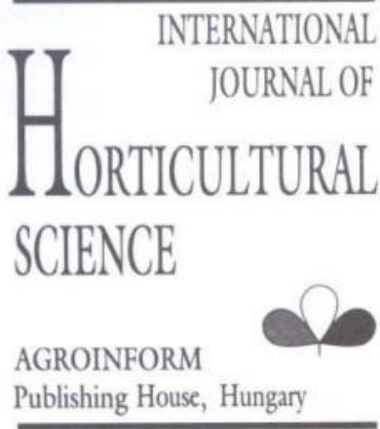

Key words: Prunus armeniaca L., breeding, genetics, inheritance, pollen sterility

Summary: Progenies (total of 1,114 seedlings) from crosses representing all possible genotypic combinations between 4 male-fertile and 1 male-sterile apricot parents were scored for the male sterility trait. Crosses between putative heterozygous normal cultivars yielded $25 \%$ of male-sterile seedlings, which supports a previous hypothesis that male sterility is controlled by a recessive allele of one nuclear locus. Crosses between those parents and putative homozygous normal cultivars did not produce any male-sterile tree. Finally, the proportion of male-sterile progeny in crosses between a male-sterile and two male-fertile cultivars depended on the genotype of the male parent. When it was heterozygous approximately $50 \%$ of the progeny was sterile, whereas when a homozygous fertile parent was used, no male-sterile progeny was obtained. These results confirm a previously proposed model, in which the male sterility trait in apricot is controlled by a single recessive gene.

\section{Introduction}

Male sterility is defined as the deviant condition in normally bisexual plants, when no viable pollen is formed (Frankel \& Galun, 1977). Male sterility has been exploited as an effective tool to aid hybrid seed production in many crops. Using this trait, seed producers can transform one inbred from a planned hybridization into a "female" line, thereby ensuring seed of hybrid origin on the male-sterile parent (Janick, 1972). However, male sterility is an undesirable characteristic in scion cultivars of Prunus, which are used for fruit production since this trait would restrict yield in large single cultivar production blocks. From the viewpoint of an apricot (Prunus armeniaca L.) breeding program male sterility is a characteristic to be avoided (Scott \& Weinberger, 1944).

Male-sterile anthers could be distinguished visually from normal fertile anthers during the bloom period. Shrunken, discolored anthers are indicative of male-sterile pollen and provide a sharp contrast to the swollen, yellow appearance of normal, pollen fertile anthers (Burgos \& Ledbetter, 1994). It has been shown before by microscopic studies, that malesterile apricots have shrunken anthers with little or no pollen (Lillecrapp et al., 1999).

A review of apricot pollen fertility (Burgos, 1991) indicated that only two male-sterile apricot varieties ('Arrogante' and 'Colorao') have been described (García et al., 1988). However, a relatively high number of male-sterile trees were observed in progenies from controlled hybridizations in apricot (Burgos \& Ledbetter, 1994). Nine different crosses with a total of 378 trees were scored for male sterility and only crosses between putative heterozygotes yielded $25 \%$ male-sterile progeny (Burgos \& Ledbetter, 1994). When the crosses studied in that paper were made, the male sterility genotypes of the parents were unknown and hybridizations were performed to combine fruit quality attributes. Since the hybridization of two Msms trees would yield $25 \% \mathrm{msms}$ individuals, it was hypothesized that pollen sterility was controlled by a single recessive gene. The allelic status of this economically important locus becomes an important factor in the efficiency of an apricot breeding program. The ability to distinguish and rogue male-sterile individuals at the seedling stage would save resources and benefit apricot breeders by increasing their program efficiency. Molecular genetic analysis of segregating populations from the planned hybridizations may provide an opportunity to establish a biochemical or genetic marker linked to this male sterility locus. Hence, in order to confirming the previously proposed hypothesis, several crosses were made and seedling populations established in the orchard. The results of the evaluation of those progenies for male sterility is described in this paper.

\section{Material and method}

Six different crosses with a total number of 1,114 trees were scored for male sterility (Table 1). Segregation of male sterility was detected in the cross between 'Gitano' and 'Pepito', two male-fertile cultivars. The rest of the crosses were planned according to the hypothesis of a recessive gene so all possible combinations between different genotypes for the trait would be represented. The putative heterozygous 
Table 1 Ratio of male fertile to male sterile seedlings from different apricot crosses.

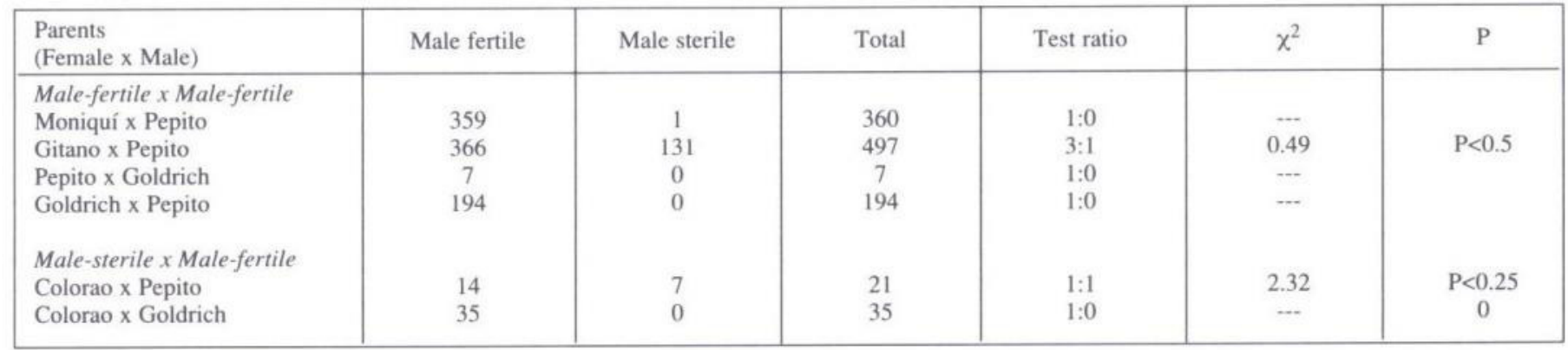

male-fertile cultivars (Msms) 'Pepito' and 'Gitano' were crossed between them. 'Pepito' was crossed with the putative homozygous male-fertile (MsMs) cultivars 'Moniquí' and 'Goldrich'. 'Pepito' and 'Goldrich' were also crossed with the homozygous male-sterile (msms) 'Colorao'.

Several samples of shrunken, discoloured anthers were chosen randomly, desiccated to dehiscence and the pollen examined.

\section{Results and discussion}

In all cases the samples with abnormal anthers failed to produce any pollen after they were desiccated.

The cross between the cultivar 'Gitano' and 'Pepito' produced progeny segregating 3 male-fertile: 1 male-sterile, whereas crosses between 'Pepito' and 'Goldrich' or 'Moniquí' did not produce male-sterile progeny. An exception to these observations was one male-sterile tree found out of 360 in the cross 'Moniquí' x 'Pepito' (Table 1).

These data confirm the heterozygous status of 'Gitano' and 'Pepito' for a recessive male sterility gene (Msms). These two cultivars could be related to 'Colorao', which is one of the few male-sterile cultivars grown commercially in Spain, since they have many similar agronomic and fruit characteristics. In addition, 'Colorao' and 'Pepito' have the same restriction fragment length polymorphism (RFLP) phenotype, except for a single RFLP band out of the 48 polymorphic fragments scored (de Vicente et al., 1998) and also in a study of RNases associated with alleles of selfincompatibility, 'Colorao' presented one band in common with each of the other two cultivars (Burgos et al., 1998).

The male-sterile tree found in the cross 'Moniquí' $x$ 'Pepito' could be explained as a seedling wrongly collected from the cross between 'Gitano' and 'Pepito', since both families were planted the same year and within the same plot.

When crosses were made using 'Colorao' as a female parent, results were very different, depending on which male parent was used. With 'Pepito', despite of the low number of seedlings in the progeny, this could be fitted to a 1:1 ratio, whereas when 'Goldrich' was used all seedlings were normal.

The results described here support the previously proposed hypothesis (Burgos \& Ledbetter, 1994), and agree with the Mendelian or "genic male sterility" model described by Frankel \& Galun (1977), in which more than 100 cases of male sterility detected and analyzed in cultivated plants showed monofactorial recessive inheritance. Scott \& Weinberger (1944) also established the inheritance of male sterility in peach as due to a single recessive. They found three male-sterile as well as 17 heterozygous peach cultivars. Nevertheless, recent research in peach has described a different type of male sterility that has been proposed to be due to cytoplasmic inheritance (Werner \& Creller, 1997). All crosses between the male-sterile parent and normal cultivars resulted in a completely male-sterile offspring. Furthermore, when these F1 seedlings were open pollinated or backcrossed with the fertile parent all progenies were male-sterile (Werner \& Creller, 1997). Cytoplasmic inheritance has been rarely documented in woody plants and we have been only able to find another report of cytoplasmic male sterility in pear (Thompson et al, 1976).

Recently the low fruit set in a clone of the 'Trevatt' cultivar of apricot has been partially attributed to male sterility. Interestingly this 'Trevatt Blue' clone seems to have originated from a mutation in the original cultivar, from which budwood was taken and trees were clonally propagated (Lillecrapp et al., 1999). A male-fertile/sterile character that is subjected to spontaneous mutations tends to support the proposed model, controlled by a single gene that would change from one form to the other after a single point mutation.

The knowledge on the inheritance of this trait will help to plan hybridizations, so that production of male-sterile progeny is avoided through selection of homozygous fertile parents. Also this information has helped to search for molecular markers for this trait that will allow to detect and rogue male-sterile plants at the seedling stage (Badenes et al., 2000).

\section{References}

Badenes, M.L., M.A. Hurtado, F. Sanz, D.M. Archelos, L. Burgos, J. Egea, \& G. Llácer. (2000): Searching for molecular markers linked to male-sterility and self-compatibility in apricot. Plant Breeding 119: 157-160.

Burgos, L. (1991): Biología floral de variedades de albaricoquero (Prunus armeniaca L.). E.T.D., S.A., Barcelona.

Burgos, L. \& C.A. Ledbetter. (1994): Observations on inheritance of male sterility in apricot. HortScience 29(2):127-127. 
Burgos, L., O. Pérez-Tornero, J. Ballester, \& E. Olmos. (1998): Detection and inheritance of stylar ribonucleases associated with incompatibility alleles in apricot. Sex Plant Reprod. 11:153-158.

de Vicente, M.C., M.J. Truco, J. Egea, L. Burgos, \& P. Arús. (1998): RFLP variability in apricot (Prunus armeniaca L.). Plant Breeding 117:153-158.

Frankel, R. \& E. Galun. (1977): Pollinitation mechanisms, reproduction and plant breeding, AnonymousMonographs on theoretical and applied genetics, 2. Springer-verlay, BerlinHeidelberg-New York.

García, J.E., J. Egea, L. Egea, \& T. Berenguer. (1988): The floral biology of certain apricot cultivars in Murcia. Adv Hort Sci 2:84-87.

Janick, J. (1972): Horticultural science. 2nd ed. W.H. Freeman and Company, San Francisco.
Lillecrapp, A.M., M.A. Wallwork, \& M. Sedgley. (1999): Female and male sterility cause low fruit set in a clone of the 'Trevatt' variety of apricot (Prunus armeniaca). Sci Hort 82: 255-263.

Scott, D.H., \& J.H. Weinberger. (1944): Inheritance of pollen sterility in some peach varieties. Proc. Amer. Soc. Hort. Sci. 45: 229-232.

Thompson, J.M., T. Van der Zwet, A.D. Draper \& R.C. Blake. (1976): Evidence of cytoplasmic and genetic male sterility in pears. J Hered 66: 259-264.

Werner, D.J. \& M.A. Creller. (1997): Genetic studies in peach: Inheritance of sweet kernel and male sterility. J Amer Soc Hort Sci 122: 215-217. 